\title{
Public Health and Private Life Under COVID-19 Vaccination Policies in China: A Legal Analysis
}

\author{
Zhengzong Huang $\mathbb{1 D}^{1, *}$ \\ Zehua Feng ${ }^{2, *}$ \\ 'Law School, Hainan University, Haikou, \\ People's Republic of China; ${ }^{2}$ School of \\ Law, Guangdong University of Finance \& \\ Economics, Guangzhou, People's Republic \\ of China
}

*These authors contributed equally to this work
Correspondence: Zehua Feng

School of Law, Guangdong University of Finance \& Economics, 2I Luntou Road, Haizhu District, Guangzhou, Guangdong Province, People's Republic of China

Email Ze-hua.Feng@outlook.com

\begin{abstract}
Vaccination against SARS-CoV-2 has been the most significant measure in the preventing and controlling the spread of COVID-19. The COVID-19 vaccination rate in China is relatively high worldwide. However, the vaccination policies behind China's effective containment of COVID-19 are not well known. Some local governments have mandated vaccination for citizens and limited the freedom of movement and other fundamental rights of the unvaccinated. This paper examines the legitimacy of mandatory vaccination policies and their institutional logic within the Chinese legal framework. China prioritizes collective rights such as health over individual rights such as privacy. However, the mandatory vaccination policies lack statutory authorization and will restrict Chinese citizens' autonomy and compromise their privacy.
\end{abstract}

Keywords: COVID-19, vaccination policy, public health, privacy, China

\section{Introduction}

The outbreak of the COVID-19 pandemic prompted the Chinese government to take numerous comprehensive and stringent preventative and control measures to contain the further spread of the virus. ${ }^{1}$ Owing to these measures, China is almost returning to normalcy. ${ }^{2}$ Indeed, China has achieved remarkable results since committing to contain domestic outbreaks of COVID-19. ${ }^{3}$ Vaccination against the virus (using 2019-nCoV vaccines) has been the most significant measure. ${ }^{4}$ According to the National Health and Wellness Commission of the People's Republic of China (PRC), 2224.081 million vaccine doses against COVID-19 had been administered in mainland China as of October $12,2021 .^{5}$ At a press conference held by the Joint Prevention and Control Mechanism of the State Council of China on September 7, 2021, Liang-you Wu, the deputy director of the Centers for Disease Control led by the National Health Commission (NHC), stated that the number of vaccinated has reached 1095 million and covered $77.6 \%$ of the national population. The COVID19 vaccination rate in China is relatively high worldwide.

China has a highly centralized political system where countrywide uniformity is preferred to regional autonomy, and the political power of the central government overwhelms that of local governments. Article 3 of the Constitution of the PRC stipulates that the functions and powers of local governments shall be under the unified leadership of the central authorities. China's central government grants local governments the authority to enforce the law and policy at the central level. Local governments must follow commands and control from the central government, though they have the necessary initiative and motivation to rule on their own. 
SARS-CoV-2 is a dangerous communicable disease with serious implications for social safety and national wellbeing, rather than merely personal health. ${ }^{6}$ As viruses can be transmitted from an infected host to other people, individual health and public health are interdependent. Given the lethality of COVID-19, several local governments in China have introduced measures to mandate vaccination against the disease and limit the freedom of movement and other fundamental rights for unvaccinated citizens. ${ }^{7}$ Besides, China has widely used health information technologies to protect public health and collect a vast amount of personal health information, including individual vaccination records. ${ }^{8-10}$ Mandatory vaccination policies are intended to protect both public and personal health. However, these policies have no statutory authorization.

This paper starts by overviewing the vaccination policies imposed by Chinese local governments, revealing specific implementation steps and the social impact of these policies. We collect these mandatory COVID-19 vaccination policies from government websites and news. And we sort them according to their jurisdictions. We then consider the rights to health and privacy, discussing legal considerations concerning mandatory vaccination policies. In the penultimate section, we offer suggestions for the Chinese government and seek to stimulate other ideas and more discussion from researchers worldwide.

\section{Conceptual Framework}

\section{Parties Involved}

China's COVID-19 vaccination policies involve three parties (Figure 1): the central government, the local governments, and the citizens. Although the National People's Congress (NPC) and the NPC Standing Committee exercise the state's legislative power, the central government (ie, the State Council) is essentially the policymaker and law enforcer. With a highly centralized political system, China's central government has supreme administrative and legal power. However, the local governments, instead of the central government, directly govern Chinese citizens. Local governments are responsible for the law enforcement in their jurisdictions and for following the commands from the central government. Chinese citizens should not only comply with the law enforced by the central government but also be subject to the policies made by them.

\section{Normative Documents}

Normative documents refer to the rules that are binding upon a large majority rather than a minority. In China's political system, the normative documents include their constitution, law, regulation, and policy. Article 8 of the Legislation Law of the PRC stipulates that only the law can restrict personal freedom or deprive a citizen's political rights with compulsory measures and penalties. Local governments have no right to establish a policy involving criminal offenses and penalties, compulsory measures, or penalties that restrict personal freedom.

\section{Legal Process}

The local governments' mandatory vaccination policies should obtain statutory authorization from the central government when the policies limit individual rights, such as the right to privacy or autonomy. No statutory authorization from the central government is necessary for the vaccination policies that do not restrict individual rights. Article 3 of the Regulation on Responses to Public Health Emergencies prescribes that when a public health emergency develops, the State Council shall set up a headquarters and be responsible for the overall leadership and command of the urgent handling of the national emergency. For public health protection, the central government can authorize local governments to establish vaccination policies that limit individual rights, except for personal freedom. However, when local governments implement mandatory vaccination policies, they lack statutory authorization and violate the principle of voluntary vaccination. In other words, they do not follow the central government's overall leadership and command.

\section{Overview of COVID-I 9 Vaccination Policies in China Local Governments' Mandatory Vaccination Policies}

In April 2021 the NHC proposed voluntary vaccination against COVID-19 based on informed consent. ${ }^{9}$ In practice, however, immunization against COVID-19 appears to be managed by local governments. For instance, several local governments have instituted parallel administrative instruments mandating COVID-19 vaccination for all residents in their jurisdictions, contrary to the central government guideline that vaccination should be voluntary. ${ }^{11}$ 


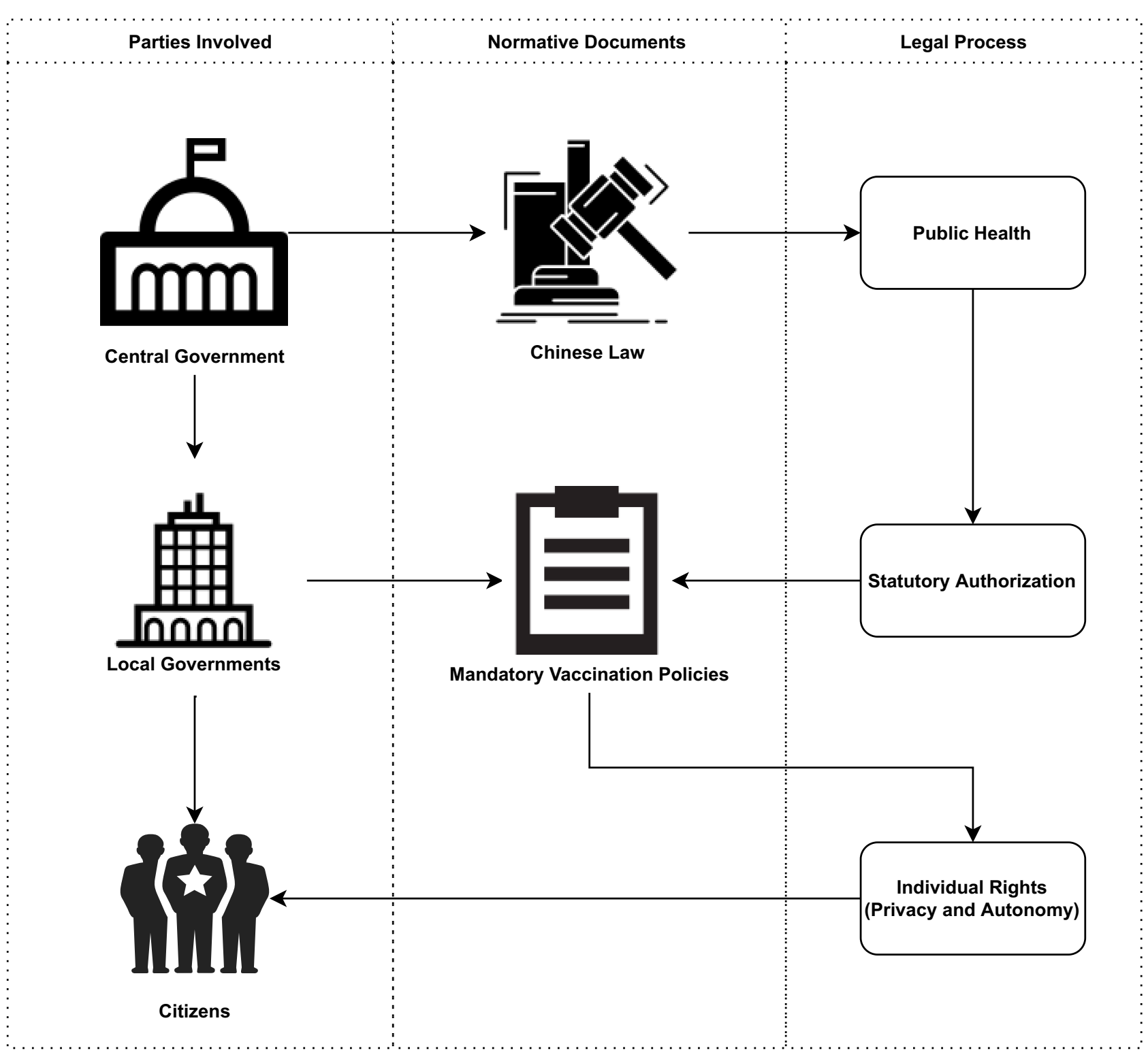

Figure I Research framework.

\section{Stage I: Mandatory Vaccination Policies Limiting the Fundamental Rights of the Unvaccinated}

Mandatory vaccination policies in State I carry the signature of administrative coercion. Local governments issue the policies with the violation of PRC Constitution and laws, attempting to mandate vaccination against the disease. In principle, unvaccinated individuals may be deprived of several fundamental rights, services, and benefits (Figure 2).

The mandatory vaccination measures introduced by local governments at grassroots level in China are outlined in Table 1.

\section{Stage II: Mandatory Vaccination Policies with Post Hoc Punishment}

After mid-July, some local governments have revised or withdrawn these policies because of public opposition. However, except for those unsuitable for vaccination, the unvaccinated individuals will suffer from post hoc punishment when they are confirmed COVID-19 infection in some areas (Figure 3). Under Articles 8 and 9 of the PRC Legislative Law, the right to punishment should only be enshrined by the laws. Local governments have no right to issue the policies with punishment. Therefore, the punitive provisions in the mandatory vaccination policies have no statutory authorization. 


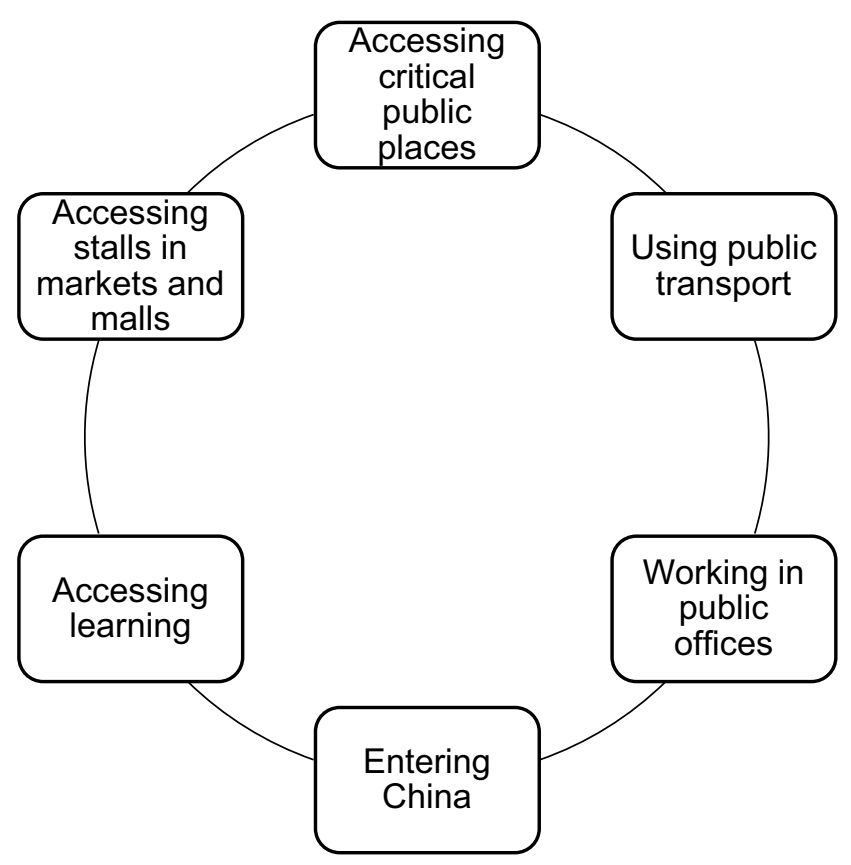

Figure 2 Restrictions on rights, services, and benefits for unvaccinated individuals.

\section{Concerns About COVID-19 Vaccines in China}

The NHC has been publishing the number of administered vaccine doses since March 2021. The rate of vaccination has risen rapidly over recent months (Figure 4). The Chinese local governments issued prolifically the mandatory COVID-19 vaccination policies between June and August (Table 1), and the vaccination rate increased rapidly in the meantime. There would be correlation between them. However, there are substantial concerns about existing COVID-19 vaccines. There is no single official public report on the data of adverse events, side effects or allergic reaction of the COVID-19 vaccine in China. According to studies, COVID-19 vaccine may cause adverse events and even severe allergic reaction. ${ }^{19,20}$

Vaccines with a long history of clinical use, such as those for rabies, cholera, and typhoid, have known contraindications and side effects. However, there are insufficient Phase III clinical data for the COVID-19 vaccine in China. Many countries have published reports of vaccination side effects, the most serious of which can cause death. ${ }^{21}$ News reports about these side effects may be the primary cause of low enthusiasm for vaccination among Chinese citizens. Gao Fu, a Chinese Academy of Sciences academician and director of the Chinese Center for Disease Control and Prevention, recommended administering the vaccine to targeted groups, rather than the whole population. ${ }^{22}$ Moreover, China's "phased victory" against COVID-19 has been founded on strict prevention and control measures, including maximal mobilization of resources for medical treatment, ${ }^{3}$ rather than vaccination.

Attempts to mandate COVID-19 vaccination have generated a significant public backlash and widespread criticism of local governments on social media. Consequently, local governments are slowly shifting toward treating vaccination as voluntary, as illustrated by Ninghai County, Zhejiang Province and Tanghe County, Henan Province, the latter revising the directive under which the unvaccinated would not be paid and would lose their jobs. ${ }^{23}$ However, all persons in Tanghe County must still show proof of immunization to enjoy public services.

\section{Health Policy, Law, and Mandatory COVID-I 9 Vaccination}

\section{The Chinese Legal Framework}

In this section, drawing on the Chinese laws outlined in Table 2, we review the legal underpinning of specific policies that directly or indirectly compel citizens to be vaccinated against COVID-19.

First, under the PRC Constitution, administrative instruments issued by local governments do not constitute Chinese laws, and so are not legally binding. None of the administrative directives listed in Table 1 have been approved by the National People's Congress (NPC) Standing Committee or the State Council of the PRC. At the early stage of the COVID-19 outbreak, all mandatory administrative instruments by local governments had to be approved by one of these two bodies.

Second, the mandatory vaccination directives introduced by local governments are against the PRC Constitution. These directives threaten to directly deprive unvaccinated citizens of basic constitutional rights, including freedom of movement (restricted use of certain public services such as public transportation), the right to education, the right to health, and the freedom to participate in cultural activities (restricted access to public libraries as well as cultural and entertainment venues). ${ }^{11}$ Restricting travel and work for unvaccinated citizens infringe their constitutional rights, such as those concerning travel, health, education, and labor. For example, on August 11, 2021, a secondary school teacher in Hangzhou (Mr. Zhang) was reported to have been subject to 15 days in administrative detention for expressing his opinion on the local governments' 
Table I Examples of Mandatory COVID-19 Vaccination Policies in China

\begin{tabular}{|c|c|c|c|}
\hline Province & Territory & Policy Details & Dates \\
\hline Henan & Tanghe County & $\begin{array}{l}\text { I. Suspension of salary and work for unvaccinated public employees } \\
\text { 2. Proof of vaccination required to enjoy public services }\end{array}$ & II July 202 I \\
\hline Zhejiang & Qingtian County & $\begin{array}{l}\text { I. COVID-19 vaccination required to enjoy public services such as access to healthcare and } \\
\text { education } \\
\text { 2. All persons coming to Zhejiang must have been vaccinated } \\
\text { 3. Restricted access to rural markets before vaccination }\end{array}$ & 21 July 2021 \\
\hline Zhejiang & Ninghai County & $\begin{array}{l}\text { I. Mandatory vaccination for public officials } \\
\text { 2. Restricted access to public and social places as well as schools }\end{array}$ & 25 July 2021 \\
\hline Jiangxi & Dingnan County & Restricted access to hospitals, schools, and other public places & 26 July 2021 \\
\hline Jiangxi & Anyuan County & Restricted access to hospitals, schools, and other public places & 26 July 2021 \\
\hline Jiangxi & $\begin{array}{l}\text { Yuehu District, } \\
\text { Yingtan City }\end{array}$ & $\begin{array}{l}\text { I. Restricted access to public places } \\
\text { 2. Persons visiting the city must be vaccinated } \\
\text { 3. Vaccination is required to run businesses }\end{array}$ & 26 July 2021 \\
\hline Jiangxi & Ruijin City & $\begin{array}{l}\text { I. Public officials to oversee mandatory vaccination of their relatives for up to three } \\
\text { generations for an unlimited period } \\
\text { 2. Mandatory vaccination of retired cadres } \\
\text { 3. Mandatory vaccination for persons aged } 18 \text { or older } \\
\text { 4. Restricted entry to critical public places such as schools and health facilities } \\
\text { 5. Mandatory vaccination for all family members of students; proof of vaccination is required } \\
\text { at the start of the academic year }\end{array}$ & 26 July 2021 \\
\hline Jiangxi & Jinggangshan City & Restricted entry to public places such as health facilities and learning institutions & 27 July 2021 \\
\hline Sichuan & Gao County & Restricted entry to public places such as health facilities and schools & 27 July 2021 \\
\hline Fujian & Jinjiang City & Restricted entry into public places & I August 202 | \\
\hline Anhui & Xuning County & $\begin{array}{l}\text { I. Restricted entry into public places } \\
\text { 2. Restricted access to public transport }\end{array}$ & I August 202 | \\
\hline Guangxi & Beiliu City & $\begin{array}{l}\text { I. Restricted entry into public places such as health facilities and schools } \\
\text { 2. Learning restricted to vaccinated individuals }\end{array}$ & | August 202 | \\
\hline Hubei & $\begin{array}{l}\text { Echeng District, } \\
\text { Ezhou City }\end{array}$ & Unvaccinated will be included in personal integrity records & I5 August 202 I \\
\hline
\end{tabular}

Notes: The information collated in Table I was extracted from reliable news outlets and official websites of various jurisdictions in China ${ }^{12-17}$.

epidemic prevention policies on the internet. ${ }^{24}$ Some local governments deprive citizens of freedom of speech to curtail public opposition, in violation of the Constitution. A further example occurred on August 15, 2021, where the local government of Echeng District, Ezhou City issued an order that failure to receive the COVID-19 vaccine without "proper reason" would be added to citizens' personal integrity records, which would limit their ability to find work or obtain a loan. ${ }^{17}$ These cited cases are blatant violations of Chinese citizens' fundamental rights by local governments seeking to ensure universal vaccination against COVID-19.

Finally, local governments' mandatory vaccination policies violate the laws of the PRC. Under the PRC Vaccination Administration Law and the Law on the Promotion of Basic Medical and Health Care, the mandate to enact and promote disease control measures is vested solely in central government. As such, local governments have no legal ground to limit any Chinese citizens' fundamental rights should they fail to be vaccinated against COVID-19. 


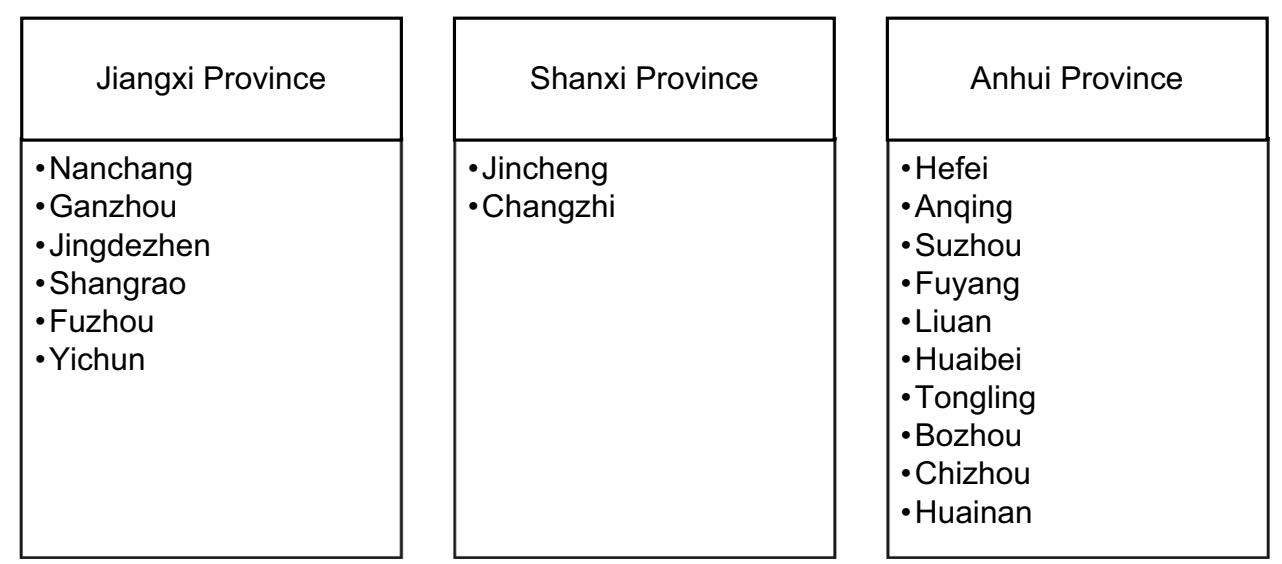

Figure 3 Local governments issued the mandatory vaccination policies with post hoc punishment. ${ }^{18}$

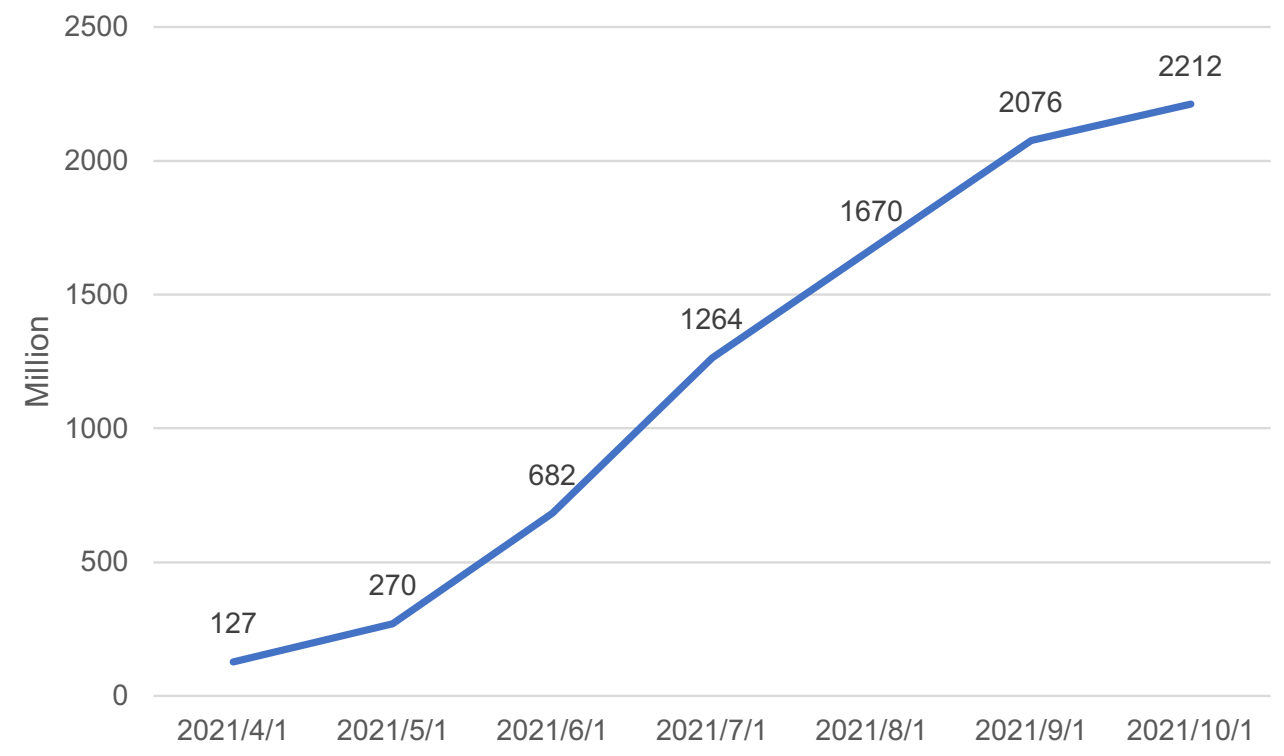

Figure 4 Trend of administered vaccine doses number in mainland China.

Notes: Data collected by the authors from NHC official website: http://www.nhc.gov.cn/xcs/yqjzqk/list_gzbd.shtml.

In summary, the mandatory vaccination policies are unconstitutional, inspire mistrust in government, and threaten to reverse the gains made in preventing and controlling the spread of COVID-19 in China. Even though the compulsive measures may be eased in the short term, local governments may see similar measures reintroduced in the future. According to Professor Shen Kui of Peking University Law School, a leading Chinese jurist, "an emergency does not justify the violation of the rule of law by governments". ${ }^{25}$ NHC clearly stated that the dual principles of full access to vaccination and the voluntariness of vaccination must be adhered to, such that people were guided and encouraged to take the initiative in getting vaccinated. ${ }^{26}$ The mandatory policies of some local governments have manifestly violated the policies of central government.

\section{Mandatory COVID-19 Vaccination Laws in the United States}

China has managed to control its COVID-19 outbreak and provide a rapid return to socio-economic development. Many countries seek to introduce mandatory vaccination policies. In the United States, Jacobson v. Massachusetts, the Supreme Court case after a smallpox outbreak in Massachusetts back in 1905, provides a legal precedent for mandatory vaccinations. The Supreme Court affirmed that the state government has the authority to compel vaccination, and that sometimes individual rights may have to yield to state laws that aim to protect public health. ${ }^{27}$ Before COVID-19, many states already had a law requiring children entering school to be vaccinated 
Table 2 China's Legal Framework for Laws on Vaccination

\begin{tabular}{|c|c|}
\hline Legal Instrument & Relevant Provision \\
\hline Constitution of the PRC & $\begin{array}{l}\text { I. The state should respect and guarantees its citizens' fundamental human rights. } \\
\text { 2. All citizens of the PRC have the freedom of movement. } \\
\text { 3. All citizens of the PRC have the right and duty to receive quality education. }\end{array}$ \\
\hline $\begin{array}{l}\text { Law of the PRC on the Prevention and } \\
\text { Control of Infectious Diseases }\end{array}$ & $\begin{array}{l}\text { I. All vaccination drives and frameworks shall be guided by the central government. } \\
\text { 2. The administrative departments of health for the State Council, provincial governments, } \\
\text { autonomous regions, and municipalities directly under the central government shall, following the } \\
\text { need to prevent and control infectious diseases, formulate corresponding measures. }\end{array}$ \\
\hline PRC Legislative Law & $\begin{array}{l}\text { Only the National People's Congress and its Standing Committee shall have the power to legislate } \\
\text { on depriving citizens of political rights and on coercive measures to restrict personal freedoms. }\end{array}$ \\
\hline $\begin{array}{l}\text { Law of the PRC on the Administration of } \\
\text { Vaccines }\end{array}$ & $\begin{array}{l}\text { I. Persons within China's territory have the right to receive vaccines under the immunization plan } \\
\text { and have the obligation to present themselves for vaccination under the immunization plan per } \\
\text { the law. } \\
\text { 2. The health department of the State Council shall formulate the national immunization plan, and } \\
\text { the vaccines must have been developed by the health department of the State Council in } \\
\text { conjunction with the financial department of the State Council. Details of the vaccine shall be } \\
\text { published after approval by the State Council. } \\
\text { 3. In case of an outbreak or epidemic of infectious diseases, local governments at or above the } \\
\text { county level or their competent health departments shall take emergency vaccination measures as } \\
\text { provided for in the Constitution and other administrative regulations. }\end{array}$ \\
\hline $\begin{array}{l}\text { Law of the PRC on Basic Medical Care and } \\
\text { Health Promotion }\end{array}$ & $\begin{array}{l}\text { I. The vaccination and immunization framework shall be implemented by the central government. } \\
\text { 2. Chinese citizens have the right and obligation to receive immunization per the law. }\end{array}$ \\
\hline
\end{tabular}

against a number of diseases, including measles, rubella, and polio. ${ }^{28}$ An adult who refuses to be vaccinated might be quarantined according to mandatory vaccination laws. ${ }^{29}$ These legislative precedents for mandatory vaccination might justify the COVID-19 vaccine requirements established by the state governments.

The government has the authority to establish mandatory vaccination laws when these laws pass the "reasonableness" test. $^{30}$ However, medical exemption and religious objection make the reconciliation of public health and individual rights difficult, challenging the "reasonableness" of COVID-19 vaccine laws. ${ }^{29}$ Besides, many people are reluctant to get immunized due to the unprecedented speed in developing COVID-19 vaccines. According to an investigation, $72 \%$ of the survey respondents express their concern about the reliability of the vaccines. ${ }^{31}$ Anthony S. Fauci, the White House's chief coronavirus medical advisor, repeatedly stated that the federal government would not centrally mandate COVID-19 vaccine requirements. ${ }^{32}$ However, the federal government developed several mandatory COVID-19 vaccination measures for all federal workers and contractors on September 9, 2021; this will affect approximately 100 million Americans. $^{33}$ The US Republican National Committee regards the mandatory vaccination measures issued by the Biden administration as unconstitutional and authoritarian. ${ }^{33}$

In the US, state governments enjoy the complete discretion to institute mandatory COVID-19 vaccination laws. The federal government only has the authority to ensure these laws do not violate the US Constitution. ${ }^{29}$ In contrast, the Chinese central government enjoys the supreme administrative power to urgently handle national public health emergencies. The local governments have limited discretion on mandatory vaccination policies. However, the mandatory COVID-19 vaccination measures must pass the "reasonableness" test (or the so-called "proportionality" test in the Chinese legal system).

\section{The Legal Considerations Behind Mandatory COVID-19 Vaccination Policies: The Right to Health and the Right to Privacy}

Health information technologies have become an increasingly popular means to respond to the COVID-19 pandemic in China, as they can identify whether residents have been vaccinated. ${ }^{8}$ Even without statutory authorization, local governments may still impose mandatory 
COVID-19 vaccination policies using health information technologies. ${ }^{34}$ For example, the Health QRcode (健康码) uses different colors to identify an individual's infection risk class, and has been commonly used in Chinese citizens' daily lives, ${ }^{35}$ they may be asked by law enforcement and public service providers to show their Health QRcode to prove their health status, low infection risk, and vaccination records (Figure 5). The empty vaccination records of unvaccinated citizens suggest they pose a higher infection risk. Although there are no laws and regulations to legally restrict the freedom of unvaccinated citizens, the managers in charge of public places (eg, restaurants, supermarkets, and schools) might refuse entry based on information in an individual's Health QRcode. Vaccination status falls within the range of the right to privacy. However, for mandatory policies by local governments, the right to privacy might be limited to protect public health.

The application of health information technologies might be an effective way to protect the right to health. ${ }^{8}$

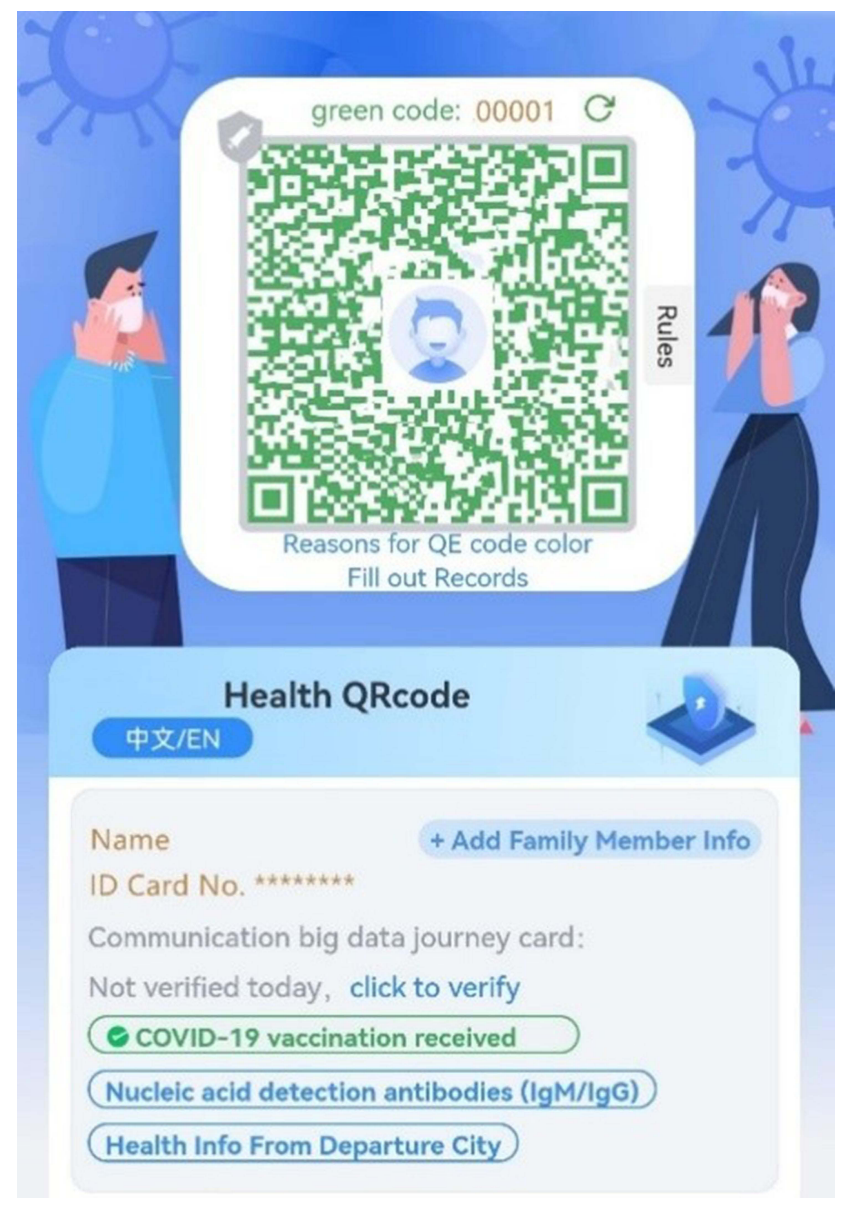

Figure 5 Health QRcode in mainland China.
Nonetheless, concerns about privacy breaches abound. ${ }^{36}$ Well-developed laws are needed to reduce the negative impacts of health information technologies on privacy.

First, the PRC Constitution stipulates the right to health as a fundamental right. The Constitution contains two types of legal protection: enabling rules and mandatory rules. The normative structure of the right to health embodies a complex framework based on the Constitution. Several provisions in the Constitution enshrine all Chinese citizens' right to health. Specifically, Articles 21, 26 , and 36 respectively stipulate that the state should (i) protect people's health, and (ii) protect and improve the environment in which people live and the ecological environment. These provisions are mandatory rules of the normative structure that indirectly protect citizens' right to health. In terms of the enabling rules, Article 45 clearly stipulates that "Chinese citizens have the right to material assistance from the state and society when they are old, ill, or disabled." Enabling rules directly protect citizens' right to health. By considering the enabling rules and mandatory rules in combination, we can conclude that the right to health cannot be negated simply because the Constitution was not meant to be taken literally and cannot substitute the substantial right with legal formalism. Legal formalism does not fully express the approach toward legally protecting the right to health provided within the Constitution. In fact, this approach to legal protection is concretized through the Civil Code and the Law on the Promotion of Basic Medical and Health Care. It is precisely because the right to health has been enshrined as fundamental that the Chinese government provides various preventative interventions to protect personal and public health, particularly when outbreaks of COVID-19 occur, no matter the cost. ${ }^{3}$ These interventions include free treatment and free vaccinations.

Second, where health information technologies collect personal data that are identifiable and private in violation of the principle of proportionality, citizens' data privacy may be threatened. ${ }^{37}$ Massive data aggregation may increase the possibility of violating privacy rights. Significant issues to consider here include the appropriate breadth of the scope of collecting personal data in general and how personal data collection can conform to the principle of proportionality. From the perspective of effective control, collecting a larger amount of personal data enables better decision-making by public healthcare providers attempting to counter the hazards of COVID-19. ${ }^{38}$ There are currently several emergent COVID-19 variants, 
which increases the difficulty of overcoming the pandemic for all countries. Without health authorities in each country collecting sufficient information, emerging COVID-19 variants cannot be effectively tracked and contained. However, the risk of data breaches is increasing with the broad scope of information collection.

Regarding data breach concerns, Chinese legislators led by the NPC have established a series of laws to protect the right to privacy, including the following prominent examples: (i) Criminal Law of the PRC, (ii) Civil Code of the PRC, (iii) Law of the PRC on the Promotion of Basic Medical and Health Care, and (iv) Public Security Administration Punishments Law of the PRC. Violations of privacy, even relatively minor, can be subject to administrative sanctions and civil penalties; severe violations may incur criminal penalties as "Provocative and Disturbing Acts" or "Violation of Personal Information Protection". ${ }^{39}$ Law enforcement can also protect personal privacy using the Cybersecurity Law of the PRC (PRC Cybersecurity Law), the Data Security Law of the PRC, and the Law of the PRC on the Protection of Personal Information. In a recent case, the Cyberspace Administration of China implemented a cybersecurity review targeting DiDi Global Inc. on July 9, 2021. Pursuant to the PRC Cybersecurity Law, DiDi was ordered to stop new users from registering, so as to reduce the risk of data breaches. ${ }^{40}$ Notably, most privacy breaches result not from inadequate national legislation on the right to privacy but from the failure of law enforcement to hold those responsible accountable Consequently, greater effort should be devoted to ensuring more vigorous law enforcement within the current Chinese legal framework, rather than excessive legislation that would make the current law more fragmented.

Finally, Chinese culture emphasizes collective rights more than individual rights. ${ }^{8}$ Accordingly, the right to privacy (perceived as individual) is subject to the right to health (regarded as collective). All COVID-19 patients in China have been receiving free treatment during the pandemic. Treated patients range from a 30-month-old infant to a man aged over 100 years old. ${ }^{2}$ The Chinese government also provides free nucleic acid testing services and large-scale vaccination. Various protective measures have been imposed during the COVID-19 pandemic. By contrast, countries that tend to prioritize individual rights over collective rights might remain in the pandemic situation for longer. China's effective containment of COVID-19 may be attributable to the priority of collective rights and the implementation of practical measures on that basis.

\section{Legislative and Administrative Actions on COVID- 19 Vaccination: Fundamental Rights Protection and Pandemic Risk Management}

Local governments' mandatory vaccination policies are undermining efforts to prevent and control the epidemic. Accordingly, the central government needs to streamline the administrative system for responding to COVID-19 in all local jurisdictions through relevant agencies. China should also enact a clear framework on vaccination against COVID-19 and comparable diseases that might subsequently emerge.

First, in consultation with medical experts and through public participation, the central government should enact laws on COVID-19 vaccination that all local governments must adopt. Local governments have no statutory authorization to formulate policies that limit Chinese citizens' fundamental rights and freedoms.

Second, the central government should incentivize rather than mandate vaccination against COVID-19 in pursuit of universal immunization. In this regard, it is important to note that local governments providing incentives such as eggs or movie tickets or using celebrities to encourage uptake of COVID-19 vaccines achieved better results. ${ }^{41}$

Third, the central government should supervise all COVID-19 vaccination drives under the existing laws. ${ }^{42,43}$ Although the NHC has provided information on the COVID-19 vaccine, potential side effects after vaccination have never been made public. ${ }^{44}$ Transparency can reduce suspicion and fading confidence in the safety of 2019-nCoV vaccines, thus promoting uptake.

Fourth, all levels of government should engage lawyers to advance public interests in the country. Lawyers promote the rule of law and social justice, which protects the right to health and privacy. Therefore, local governments should engage lawyers to strengthen public awareness of existing laws and regulations on preventing and controlling infectious diseases, emergency response, and general security management. This can inspire citizens' confidence in the governments' vaccination drive. Local governments should also seek legal advice on their role in the prevention and control of COVID-19 in China.

Finally, the state should establish a social compensation framework for victims of major public emergencies. Those who manifested severe allergic reactions can receive compensation from the state. This can benefit victims of physical or mental damage caused by the COVID-19 vaccine. 
Although some cities have withdrawn mandatory vaccination policies under the scrutiny of news media, ${ }^{45}$ other cities continue to use such policies to compel vaccination. ${ }^{46}$ The COVID-19 vaccines were developed less than two years ago and have unknown side effects. Therefore, vaccination policies in any country should be based on incentivizing, rather than compelling, uptake.

\section{Conclusion}

This paper's purpose was to examine the legitimacy of mandatory vaccination policies and their underlying institutional logic. These mandatory policies may be a key reason for China achieving such a high vaccination rate. China is a socialist country that highly emphasizes collective interests and group harmony, prioritizing collective rights such as health over individual rights such as privacy. Based on this jurisprudential foundation, Chinese local governments are using administrative or policy measures to collect personal health information. ${ }^{10}$ These measures have restricted the freedom of movement for unvaccinated citizens but increased the vaccination rate and enhanced vaccination coverage. Limitations on fundamental rights are thus helpful in restricting the spread of COVID-19. However, mandatory vaccination policies without statutory authorization both restrict Chinese citizens' autonomy and compromise their privacy.

With regard to our study's methods, some limitations need to be acknowledged. We searched primary literature to collate details of mandatory vaccination directives against COVID-19 by Chinese local governments. Some of these policies have been revised or withdrawn because of public opposition. We could not collect accurate data on the number of individuals coerced into being vaccinated. According to the official information disclosure system, Chinese local governments consider many details on vaccination to be state secrets. Thus, we cannot determine how severely citizens' rights and freedoms have been limited. Finally, we focus on the normative functions of law, rather than the social functions. Despite these limitations, this paper certainly adds to our understanding of China's success in containing COVID-19 and the regrettable deficiencies of related policies. Further empirical research is needed to estimate the practical effects of mandatory vaccination policies imposed by Chinese local governments.

\section{Acknowledgments}

This research was funded by the 2021 Guangdong General University Young Innovative Talents Project (Grant
No. 2021WQNCX020), the Foshan Social Science Planning Project (Grant No. 2021-GJ086), and the Guangdong Key Discipline Research Project (Grant No. 2019-GDXK-0005).

\section{Disclosure}

The authors report no conflicts of interest in this work.

\section{References}

1. Xin X, Li SF, Cheng L, et al. Government intervention measures effectively control COVID-19 epidemic in Wuhan, China. Curr Med Sci. 2021;41(1):77-83. doi:10.1007/s11596-021-2321-6

2. The State Council Information Office of the People's Republic of China. Fighting COVID-19: China in action. Available from: http:// english.www.gov.cn/atts/stream/files/5edc549dc6d0cc300eea778c. Accessed October 20, 2021.

3. Zhang S, Wang Z, Chang R, et al. COVID-19 containment: China provides important lessons for global response. Front Med. 2020;14 (2):215-219. doi:10.1007/s11684-020-0766-9

4. Kaufman J, Attwell K. Maintaining routine vaccination during the COVID-19 pandemic. Med $J$ Aust. 2021;214(2):93-93.e91. doi:10.5694/mja2.50919

5. National Health Commission of the People's Republic of China. COVID-19 vaccination status; 2021. Available from: http://www. nhc.gov.cn/jkj/s7915/202110/aa8c8f586ea84c81bd6b0fec842724e1. shtml. Accessed October 20, 2021.

6. Madabhavi I, Sarkar M, Kadakol N. COVID-19: a review. Monaldi Arch Chest Dis. 2020;90(2). doi:10.4081/monaldi.2020.1298

7. Pingdingshan Weiyou Quan. Mandatory vaccination requirements, these officials are collective antilogy! Available from: https://www. 163.com/dy/article/GF534B0Q05383UVE.html. Accessed October 20, 2021.

8. Shen T, Wang C. Big data technology applications and the right to health in China during the COVID-19 pandemic. Int $J$ Environ Res Public Health. 2021;18(14):7325. doi:10.3390/ijerph18147325

9. Xinhua. China encourages voluntary COVID-19 vaccination: official. Available from: https://www.chinadaily.com.cn/a/202104/12/ WS6073a294a31024ad0bab4ce6.html. Accessed October 20, 2021.

10. Xu W, Wu J, Cao L. COVID-19 pandemic in China: context, experience and lessons. Health Policy Technol. 2020;9(4):639-648. doi:10.1016/j.hlpt.2020.08.006

11. Mao WD, Guo J. Analysis of popular opinion: how several places are responding to normal travel and even children's schooling being affected for those who have not been vaccinated. Available from: https://www.thepaper.cn/newsDetail_forward_13902207. Accessed October 20, 2021.

12. THE PAPER. Many places have vaccination requirements for public officials: suspension of salary and the deadline for vaccination of relatives within three generations. Available from: https://baijiahao. baidu.com/s?id=1705264933423536593\&wfr=spider\&for $=$ pc. Accessed October 20, 2021.

13. HEXUN. Notices in many parts of China: the unvaccinated will not be able to enter hospital inpatient units, nursing homes, schools. Available from: https://baijiahao.baidu.com/s?id= $1705221991763465979 \& w f r=$ spider\&for=pc. Accessed October 20, 2021.

14. THE PAPER. Notices from several districts and counties of Fujian: those who have not received the COVID-19 vaccine will be restricted from entering key public places. Available from: https://baijiahao. baidu.com/s? id=1705250528343100574\&wfr=spider\&for=pc. Accessed October 20, 2021. 
15. SOHU. Attention! These people in Yingtan Yuehu District will be restricted from traveling tomorrow! Available from: https://www. sohu.com/a/479518356_121123744. Accessed October 20, 2021.

16. CCTV. Many places notified that the unvaccinated might affect travel, mandatory vaccination coming? Five districts and counties respond. Available from: https://m.thepaper.cn/baijiahao_13560932. Accessed October 20, 2021.

17. Echeng District Government. Including those who do not receive the COVID-19 vaccine without proper reason into personal integrity records. Available from: https://www.thepaper.cn/newsDetail_for ward_14084341. Accessed October 20, 2021.

18. THE PAPER. Three days 24 places to issue notices! The COVID-19 infected individuals in these situations will face severe penalties. Available from: https://m.thepaper.cn/baijiahao_14153518. Accessed October 20, 2021.

19. Shimabukuro T, Nair N. Allergic reactions including anaphylaxis after receipt of the first dose of Pfizer-BioNTech COVID-19 vaccine. JAMA. 2021;325(8):780-781. doi:10.1001/jama.2021.0600

20. Cabezas C, Coma E, Mora-Fernandez N, et al. Associations of BNT162b2 vaccination with SARS-CoV-2 infection and hospital admission and death with covid-19 in nursing homes and healthcare workers in Catalonia: prospective cohort study. BMJ. 2021;374: n1868. doi:10.1136/bmj.n1868

21. Schultz NH, Sørvoll IH, Michelsen AE, et al. Thrombosis and thrombocytopenia after ChAdOx1 nCoV-19 vaccination. $N$ Engl $J$ Med. 2021;384(22):2124-2130. doi:10.1056/NEJMoa2104882

22. Gao F. There is no conclusion whether ADE phenomenon occurs after vaccination. Available from: https://3g.163.com/v/video/VZTOR03EU. html. Accessed November 3, 2021. Accessed October 20, 2021.

23. Tanghe County Government. 'No vaccination, no pay, no job': notice not implemented and has been corrected. Available from: https:// tanghe.gov.cn/thyw/54943.html. Accessed October 20, 2021.

24. Cheng P. "Let Yangzhou test abandon strict epidemic prevention and live with the virus." A teacher in Jiangxi was detained for 15 days for epidemic-related remarks, and he apologized. Available from: http:// www.nbd.com.cn/articles/2021-08-12/1874111.html. Accessed October 20, 2021.

25. Shen K. Restrictions on travel by unvaccinated people everywhere are against the rule of law. Available from: https://www.163.com/dy/ article/GEVP25SV0514BE2Q.html. Accessed November 3, 2021. Accessed October 20, 2021.

26. National Health Commission of the People's Republic of China. Transcript of the press conference of the Joint Prevention and Control Mechanism of the State Council on April 11, 2021. Available from: http://www.nhc.gov.cn/xcs/fkdt/202104/ d279e3354a5645828b671bf8bd15cbdb.shtml. Accessed October 20, 2021.

27. Rosen J. Can COVID-19 vaccines be mandatory in the U.S. and who decides? Available from: https://publichealth.jhu.edu/2020/can-covid -19-vaccines-be-mandatory-in-the-us-and-who-decides. Accessed October 20, 2021.

28. Hodge JG, Gostin LO. School vaccination requirements: historical, social, and legal perspectives. KY Law J. 2001;90(4):831-890.

29. Cole JP, Swendiman KS. Mandatory vaccinations: precedent and current laws. Available from: https://sgp.fas.org/crs/misc/RS21414. pdf. Accessed October 20, 2021.

30. Roos D. When the supreme court ruled a vaccine could be mandatory. Available from: https://www.history.com/news/smallpox-vaccinesupreme-court. Accessed November 3, 2021. Accessed October 20, 2021.
31. Pawlowski A. Can an employer mandate the COVID-19 vaccine? Available from: https://www.today.com/health/will-covid-19-vaccinebe-mandatory-t190838. Accessed October 20, 2021.

32. Wang AB. Fauci says there should be more covid vaccine mandates at the local level. Available from: https://www.washingtonpost.com/ politics/2021/07/11/fauci-says-there-should-be-more-covid-vaccinemandates-local-level/. Accessed October 20, 2021.

33. Watson K. Biden announces COVID-19 vaccine mandates that will affect 100 million Americans. Available from: https://www.cbsnews. com/live-updates/biden-covid-19-vaccine-mandates-announcement/. Accessed October 20, 2021.

34. Yu X, Li N, Dong Y. Observation on China's strategies to prevent the resurgence of the COVID-19 epidemic. Risk Manag Healthc Policy. 2021;14:2011-2019. doi:10.2147/RMHP.S305413

35. Liang F. COVID-19 and health code: how digital platforms tackle the pandemic in China. Soc Media Soc. 2020;6(3):2056305120947657.

36. Bassan S. Data privacy considerations for telehealth consumers amid COVID-19. J Law Biosci. 2020;7(1):Isaa075. doi:10.1093/jlb/lsaa075

37. Stoeger K, Schmidhuber M. The use of data from electronic health records in times of a pandemic-a legal and ethical assessment. J Law Biosci. 2020;7(1):1saa041. doi:10.1093/jlb/lsaa041

38. Bragazzi NL, Dai H, Damiani G, Behzadifar M, Martini M, Wu J. How big data and artificial intelligence can help better manage the COVID-19 pandemic. Int J Environ Res Public Health. 2020;17 (9):3176. doi:10.3390/ijerph17093176

39. Wang Y. Seven people sentenced for telecoms scam that caused schoolgirl's suicide, main culprit sentenced to life. Available from: www.bjnews.com.cn/detail/155152531714557.html. Accessed Octo ber 20, 2021.

40. Cyberspace Administration of China. Notice on the takedown of "DiDi Chuxing" App. Available from: www.cac.gov.cn/2021-07/04/ c_1627016782176163.htm. Accessed October 20, 2021.

41. Uzaobao. Shanghai invites idol girl group to promote vaccination and to encourage people to get vaccinated. Available from: http://www. czaobao.com/shiju/20210503/91688.html. Accessed November 3, 2021. Accessed October 20, 2021.

42. Bolleyer N, Salat O. Parliaments in times of crisis: COVID-19, populism and executive dominance. West Eur Polit. 2021;44(56):1103-1128. doi:10.1080/01402382.2021.1930733

43. Mazraani M, Barbari A. Anti-Coronavirus disease 2019 vaccines: need for informed consent. Exp Clin Transplant. 2021;19 (8):753-762. doi:10.6002/ect.2021.0235

44. National Health Commission of the People's Republic of China. Novel Coronavirus vaccination adverse reaction knowledge Q\&A. Available from: http://www.nhc.gov.cn/xcs/nwwd/202105/ 649d52fda79940548f68751afe8811a1.shtml. Accessed October 20, 2021.

45. Dai X, Jiang HZ, Hu XH. Can't go to school, see a doctor, or get paid without the COVID-19 vaccine? Many places have withdrawn their local policies. Available from: https://www.bjnews.com.cn/detail/ 162641956814935.html. Accessed October 20, 2021.

46. Geishui. The Central Commission for Discipline Inspection has just reiterated that vaccination should be voluntary, but some local school boards have topped the trend. Parents are highly opposed to it. Available from: https://www.163.com/dy/article/ GF939T7L0534GPGU.html. Accessed October 20, 2021. 


\section{Publish your work in this journal}

Risk Management and Healthcare Policy is an international, peerreviewed, open access journal focusing on all aspects of public health, policy, and preventative measures to promote good health and improve morbidity and mortality in the population. The journal welcomes submitted papers covering original research, basic science, clinical \& epidemiological studies, reviews and evaluations, guidelines, expert opinion and commentary, case reports and extended reports. The manuscript management system is completely online and includes a very quick and fair peer-review system, which is all easy to use. Visit http://www.dovepress.com/testimonials.php to read real quotes from published authors. 